\title{
Interseccionalidades nas Q uadrilhas Juninas em Aracaju/SE: Gênero, Geração e Sexualidades
}

\author{
Liana Matos Araújo ${ }^{1}$
}

\section{Resumo}

O presente artigo é um estudo sobre as temáticas do gênero e da geração que se tornaram pontos diacríticos durante uma pesquisa de campo junto aos quadrilheiros de Aracaju/SE. Para isso, toma-se a insterseccionalidade como a forma de articular temas aparentemente distintos, porém relacionáveis, entre os membros da instituição quadrilha junina. Pensar de forma interseccional possibilitará perceber como essas categorias estão interligadas e imbricadas nas práticas e sociabilidades das juventudes da Quadrilha Junina Apaga Fogueira. Desta maneira, a ideia é não fragmentar e nem hierarquizar uma categoria ou outra, mas entender como se dão as relações sociais entre elas mediante a transfiguração de alguns membros do sexo masculino vestidos com os trajes destinados ao sexo feminino tanto durante os ensaios quanto nas apresentações.

Palavras-chave: gênero, geração, interseccionalidades, culturas juvenis, quadrilha junina.

1 Membro do GERTS - Grupo de Estudos Culturais, Identidades e Relações Interétnicas. Mestre em Antropologia. liana.matos2@gmail.com 


\section{Intersectionalities Inside the June square-dance in Aracaju/SE: Gender, Generation and Sexualities}

\section{Abstract}

The present article is a study of the themes of gender and generation that have become diacritical points during a field research along with the members of the June square-dance in Aracaju/ SE. In order to do so, the intersectionality is considered the way to articulate apparently distinct themes, but relatable, among the members of the institution June square-dance. Thinking on an intersectional way will enable the understanding of how these categories are interrelated and interlaced in the practices and sociabilities of the youth of the June square-dance Apaga Fogueira. Thus, the idea is neither to fragment nor to create a hierarchy between one category or another, but to understand how the social relations work among them through the transfiguration of some members of the male sex dressed in costumes assigned to the female sex, both during rehearsals, and in the presentations. Keywords: gender, generation, intersectionalities, juvenile cultures, the June square-dance.

\section{Introdução}

Conflitos geracionais, diferenças sexuais, diversas faixas etárias e hierarquização de poderes foram assuntos visíveis entre os quadrilheiros de Aracaju/SE e manifestados em seus momentos de sociabilidades. Ao vivenciar suas práticas durante a pesquisa de campo para compor a dissertação ${ }^{2}$, que versou sobre a análi-

2 Dissertação apresentada ao Programa de Pós-Graduação em Antropologia da Universidade Federal de Sergipe como parte dos requisitos necessários para obtenção do título de mestre em Antropologia. Sob a orientação do Prof. Dr. Frank Nilton Marcon. 
se do sentido dado a categoria juventude pelos quadrilheiros de Aracaju/SE, surgiram estes temas tangenciais: o gênero, a geração e a faixa etária que iam além dos quais eu estava pesquisando no momento.

Essa pesquisa de campo foi realizada no ano de 2014, entre os meses de fevereiro e julho, e desenvolveu-se em etapas: 1) um pré-campo foi realizado no mês de fevereiro, o que resultou na escolha da quadrilha junina a ser estudada; 2) o acompanhamento da quadrilha nos ensaios entre os meses de fevereiro e junho. Esse momento envolveu observação direta e entrevistas com os participantes das quadrilhas. Essas entrevistas seguiram um roteiro elaborado previamente, porém foram realizadas de forma aberta. A elaboração do diário de campo ${ }^{3}$ se tornou indispensável para compreensão do processo de análise e como registro da observação realizada para a pesquisa; 3) Por último, acompanhei e observei a quadrilha durante a sua participação nos concursos de quadrilha junina.

Assim, o artigo aqui apresentado é fruto de um estudo traçado durante a composição da dissertação de mestrado e centra-se no debate sobre a temática do gênero e da geração a partir da teoria das interseccionalidades na busca pela articulação de temas aparentemente díspares que se apresentaram no momento da pesquisa de campo como sinais diacríticos da quadrilha em questão.

Pensar em gênero na quadrilha junina foi algo que emergiu a partir das imersões em campo, porém se mostrou relevante por complementar um aspecto relacional importante no cotidiano das quadrilhas e dos quadrilheiros de Aracaju/SE. Assim, abordo a quadrilha junina enquanto uma manifestação cultural, uma

30 diário de campo contemplou todos os olhares no momento do pré-campo dessa Dissertação. Funcionou como um apanhado do todo que se mostrava ao pesquisador e despertou para situações variadas e diferenciais da quadrilha em questão. 
organização social e política que está presente em vários estados brasileiros, em que o interesse é entender quais os papéis sociais, as relações de poder e a interação entre os jovens no contexto de uma quadrilha junina. ${ }^{4}$

A quadrilha junina funciona como um espaço social de lazer para a comunidade onde ela está sediada. Ela se torna o lugar de encontro dos jovens, da comunidade e de indivíduos de outros bairros nos fins de semana para ensaios, reuniões e bingos para arrecadar fundos, entre outras atividades. Para Feixa (2004), os espaços de sociabilidades das juventudes servem para entender como os jovens dão simbologia às suas expressividades. Um fato interessante é que o espaço evidencia seu poder comunicativo à proporção que ele funciona como um meio de comunicação. Nele não há somente uma troca de símbolos e de informações, mas também uma interação entre diversos grupos sociais (Ferreira, 2005).

De acordo com Magnani (2005), o jovem busca os espaços, as instituições, os agrupamentos e, aqui, a instituição quadrilha junina, para emergir enquanto sujeito na busca por reconhecimento coletivo. Ao buscarem esse reconhecimento, os jovens que estão nas quadrilhas procuram uma forma de serem notados por seus amigos, colegas e familiares. A quadrilha funciona como um espaço de produção de sentido para os jovens da cidade de Aracaju ao possibilitar a reinvenção dos espaços de convivência já conhecidos entre eles.

Assim, tomando a quadrilha enquanto um espaço de sociabilidades que proporciona a interação entre seus membros pretende-se: 1) verificar se a questão geracional tem função importante nas re-

4 Segundo Cascudo (1988, p. 743), a quadrilha é "A grande dança palaciana do século XIX, protocolar, abrindo os bailes da corte, em qualquer país europeu ou americano, tornada preferida pela sociedade inteira, popularizada sem que perdesse o prestígio aristocrático, vivida, transformada pelo povo que lhe deu novas figuras e comandos inesperados, constituindo o verdadeiro baile em sua longa execução de cinco partes, gritadas pelo "marcante", bisadas, aplaudidas, desde o palácio imperial aos sertões." 
lações sociais estabelecidas; 2) descrever a relação entre ser quadrilheiro e suas sociabilidades na quadrilha mediante as diversas gerações encontradas; 3) e, por fim, identificar, a partir das interseccionalidades, como são tratadas as questões sobre o gênero e sua relação com a noção de juventude, de geração e de sexualidade.

Para isso, durante a pesquisa, adotei as seguintes estratégias metodológicas: levantamento bibliográfico e documental; entrevistas abertas amparadas por um roteiro elaborado previamente e distinto para cada segmento que foi observado; observação direta junto à quadrilha Apaga Fogueira ${ }^{5}$ com a escrita de um diário de campo; pesquisa em fontes virtuais com busca em sites, blogs e redes sociais, com o intuito de estar ciente das competições de quadrilhas juninas no Estado, debruçar o olhar sobre as publicações da quadrilha estudada e dos organizadores das competições.

\section{A Q uestão Geracional na Q uadrilha Junina Apaga Fogueira}

A noção de geração é comumente entendida pela ideia de conjunto de pessoas em uma mesma fase da vida com idades próximas e vivenciando o mesmo momento. Um conceito aparentemente simples quando observado pelo senso comum. Entretanto, incluir determinada pessoa numa geração conota a ideia de contemplação dos mesmos ideais, valores sociais e gostos. Uma conotação duvidosa se analisarmos pelo viés das culturas juvenis já que uso a perspectiva para denominar as juventudes como múltiplas, diversas e heterogêneas (Pais, 2003).

5 A Quadrilha Junina Apaga Fogueira está presente no cenário das quadrilhas juninas de Aracaju/SE desde 1982. Conta com 40 integrantes em cena, mais a diretoria e os auxiliares nos bastidores, totalizando, aproximadamente, 50 integrantes compostos por diversas faixas etárias. Por não possuírem sede própria, os encontros são realizados em uma escola da rede municipal aos domingos e no centro comunitário do Bairro América, bairro periférico, as terças e quintas à noite. No período da pesquisa de campo esses ensaios são intensificados e mais recorrentes. 
É importante entender que dentro de um mesmo grupo, como no caso da Apaga Fogueira, podemos encontrar trajetórias de vida distintas, expressas ou não na concepção de juventude, o que pode sugerir também a existência de gerações também distintas. 0 termo geração foi utilizado de diferentes maneiras em várias áreas do conhecimento. No pensamento sociológico, por exemplo, esse conceito foi sendo construído por alguns autores como Comte, Dilthey e Mannhein. De acordo com Feixa e Leccardi (2010), os primeiros escritos sobre o termo são: Comte, numa visão mais positivista e Dilthey numa abordagem histórico-romântica.

De acordo com Feixa e Leccardi (2010) "o tempo biográfico e o tempo histórico fundem-se e transformam-se criando desse modo uma geração social" (Feixa e Leccardi, 2010, p. 7). De acordo com os autores, os indivíduos que faziam parte de uma determinada geração podiam ter consciência que participavam dela. A consciência geracional era o termo utilizado para definir esse processo no qual o indivíduo consegue se perceber no mundo. Ou seja, "uma dimensão, que por sua natureza, enfatiza uma abordagem reflexiva - envolve a consciência de sua proximidade/distância de outras gerações" (Feixa e Leccardi, 2010, p. 9). Estar ciente de qual geração se está compartilhando experiências é poder estabelecer uma relação com uma ideia de passado e futuro, por exemplo, com as gerações anteriores e as que estarão por vir.

Ter relação com o passado ou com as gerações anteriores é uma forma de perceber como se dá a relação entre gerações diferentes no seio familiar, por exemplo. Na instituição quadrilha junina, no caso da Apaga Fogueira, desde a fundação que sua regência está a cargo dos familiares da Presidente e fundadora. Assim, eles produziram ao longo dos anos uma memória ${ }^{6}$ sobre a qua-

6 As narrativas colhidas na pesquisa de campo revelam que, para um mesmo evento vivenciado coletivamente, as pessoas têm recordações diferenciadas, a depender das suas referências. A memória coletiva possibilita a criação de uma memória individual. 
drilha, os festejos e as manifestações em Sergipe, ao passo que foram transmitindo às novas gerações que surgiam ao longo dos 32 anos de instituição, a memória que construíram. De acordo com Feixa e Leccardi (2010):

A memória familiar personifica a continuidade entre as gerações; previne a exacerbação das diferenças; protege a unidade do grupo. Além disso, através da afetividade, o caráter normativo da transmissão é sustentado e as "imagens de mundo" nela contida são fortalecidas. (Feixa e Leccardi, 2010, p. 9).

No trabalho de campo ficou visível a importância da família e, por sua vez, da direção da quadrilha. Eles eram vistos como os responsáveis por manter a unidade do grupo frente às mudanças ocorridas ao longo dos anos no processo de reconfiguração das quadrilhas juninas. Ou seja, mesmo adaptando seus figurinos, mudando sua estética, modernizando sua aparelhagem tecnológica e respeitando as orientações sexuais, é na geração da família que a dirige que os integrantes enxergam a unidade da quadrilha em questão, ao suscitar a existência dela frente a tanta modificação e em uma aparente manutenção da tradição. Entretanto, não significa dizer que não haja tensões geracionais na Apaga Fogueira.

Dessa forma, a partir do campo e com base em tal leitura, percebi a presença de gerações distintas comungando de um mesmo objetivo: estar na quadrilha junina. Na quadrilha Apaga Fogueira a palavra geração foi mencionada em algumas entrevistas e evocada por integrantes em seus momentos de socialização, comumen-

Percebe-se a importância de se analisar o fenômeno com grupos de pessoas, pois, ao se reunirem, elas podem lembrar um determinado fato, até sua sequência e estrutura, à medida que conversam (Halbwachs, 2006). Dessa forma, tenta-se mostrar aqui como a memória é relevante na perpetuação de alguns valores e anseios no processo de continuidade e descontinuidade de uma geração. 
te associada à idade de seus integrantes. Segue abaixo um gráfico representativo da faixa etária, ao considerar os grupos de idade com base na definição do ECA, do $\operatorname{EJUVE}^{7}$ e do Estatuto do Idoso.

Figura 1: Gráfico da faixa etária dos integrantes da Apaga Fogueira.

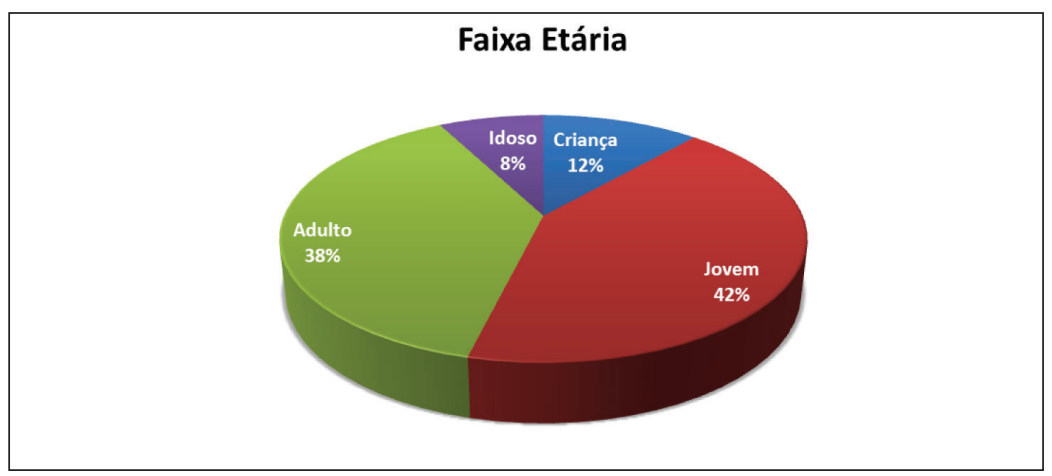

Ilustração: Uelton Carvalho.

A partir do gráfico acima, depreende-se que a quadrilha junina estudada tem um número maior de componentes na fase da vida que compreende entre 15 e 29 anos de idade. Isso se torna reflexo não somente nas mudanças ocorridas na manifestação, mas também na vivência entre eles e os outros grupos de idade. Isto é, no caminho dos estudos juvenis fica notável que, enquanto uma categoria sociológica, ela nunca foi tratada por si só, mas sempre em relação às outras faixas de idade.

Falar em geração, quando abordamos as juventudes, remete sempre a uma ideia relacional e, na Apaga Fogueira, isto se tornou visível entre os quadrilheiros. Mesmo que eles utilizem a palavra geração como sinônimo de grupo etário, deixavam transparecer que havia diferenças entre estes grupos porque

7 ECA: Estatuto da Criança e do Adolescente. EJUVE: Estatuto da Juventude. 
eles tiveram experiências de vida díspares, em épocas distantes e momentos culturais diferenciados. Essa analogia estava presente nas narrativas quando eles se referiam uns aos outros como, por exemplo, "no meu tempo não era assim, na minha época ninguém atrasava para os ensaios". Dessa forma, a partir do gráfico acima, que suscita muito mais que uma quantidade de pessoas, nota-se a existência de vivências e modos de ser diferentes que, por sua vez, convivem simultaneamente com objetivos coletivos, como o fato de estar participando de alguma forma da manifestação. Tudo isso compartilhado num único espaço social - a quadrilha junina.

Dentro desse debate sobre as gerações e suas diferenciações uma categoria flutuante foi percebida em campo - a questão do gênero. A convivência entre diferentes gerações suscitou algumas problemáticas dentro da pesquisa que convergiram para a percepção sobre outras diferenças presentes entre seus integrantes, como os significados do gênero.

\section{Gênero e Interseccionalidades na Apaga Fogueira.}

Durante a pesquisa de campo ficou perceptível a presença de jovens do sexo masculino que se autodeclaravam homossexuais e se vestiam com o figurino destinado às mulheres para dançar com um par na quadrilha. 0 gráfico abaixo demonstra que 5\% dos bailarinos masculinos dançam como mulheres nas apresentações da Apaga Fogueira. Na configuração cênica e performática das quadrilhas juninas os casais são sempre compostos por uma heteronormatividade visto que não há casal formado por pessoas do mesmo sexo. 0 que está ocorrendo com algumas quadrilhas é que alguns homens estão se travestindo de mulher, o que ocasiona numa transcendência do sentido de sexo biológico e de gênero enquanto uma construção social deste sexo biológico.

Nesse sentido, sexo e gênero se encontram por vezes em oposições. Essa oposição foi abordada e criticada por Butler (2005) e 
sua principal discussão centra-se na distinção entre sexo, abordado como algo natural, e gênero como algo construído socialmente presente nos movimentos feministas. A partir disso, ela constrói uma narrativa crítica a respeito dessa conceitualização buscando quebrar com essa naturalização do sexo. Ela parte para uma indicação que o sexo também seria cultural e discursivo como o gênero. Assim, ela se debruça sobre a desconstrução da heteronormatividade através de atos subversivos.

Dessa forma, é importante observar essa situação relacionada ao sexo e ao gênero, já que a instituição quadrilha junina se torna um espaço social que propicia sociabilidades e vivências juvenis e dita normas e regras a seus membros. Ou seja, "a experiência é o lugar da formação do sujeito" (Brah, 2006, p. 360) e a quadrilha se torna, assim, parte fundante também na formação do ator social. Portanto, a análise de como se reconfiguram as diferenças entre os membros integrantes da Apaga Fogueira se tornou fator evidente na pesquisa de campo como se apresenta no gráfico abaixo:

Figura 2: Gráfico referente ao sexo biológico dos integrantes da Apaga Fogueira. ${ }^{8}$

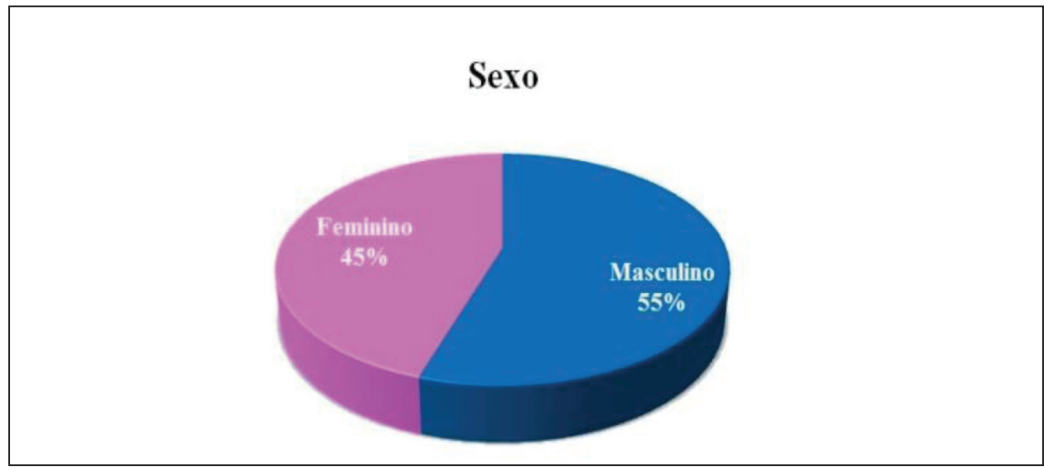

Ilustração: Uelton Carvalho.

8 As informações contidas no gráfico referem-se ao dia da apresentação que contou com 40 integrantes. 
De acordo com Piscitelli (2008), falar sobre gênero remete a uma preocupação em saber como se deu o processo histórico de construção teórica desta categoria. Segundo ela, os estudos mais críticos sobre gênero ganham espaço na discussão acadêmica a partir de 1980 quando várias autoras feministas ${ }^{9}$ remontam a trabalhos já escritos e legitimados e os questionam, criticam e propõem novas abordagens. Nessas novas proposições estão a distinção entre sexo e gênero, a quebra da ideia de poder universal e o fim da noção de um sujeito universal. Segundo ela, essas novas discussões teóricas estavam em paralelo com as mudanças a respeito das reivindicações de movimentos feministas sobre a diferença.

O debate segue então na tentativa de desmistificação em que o gênero vinha sendo pensado, como uma categoria superior às outras e no antagonismo masculino/feminino. Abandonar essa distinção única seria necessário, para Butler (2002), haja vista que a conceptualização de gênero se dá, para ela, de forma relacional não somente entre a oposição do sexo biológico, homem e mulher, mas na oposição entre pessoas do mesmo sexo, por exemplo.

Segundo Brah $(2006)^{10}$, as categorias negro e gênero foram criadas para representar um todo diverso, diante de generalizações equivocadas. De acordo com ela, nos anos de 1990, "o debate mudou radicalmente, e, essas "tipologias" adquirem um interesse histórico" (Brah, 2006, p. 343). Assim, buscar

9 Autoras como "Scott (1998) entre as historiadoras, Strathern (1998) na antropologia, a Haraway (1991), na história da ciência, a Butler (1990), na filosofia. Algumas dessas autoras esperavam, valendo-se do trabalho com gênero, produzir deslocamentos nos paradigmas disciplinares no marco dos quais trabalhavam" (Piscitelli, 2008, p. 263).

10 Em seu artigo sobre a diferença, diversidade e diferenciação, Brah (2006) analisa a construção histórica da categoria negro em paralelo com a constituição dos movimentos feministas. Essa necessidade de conhecer as esferas fundantes de tais categorias deve-se ao fato dela utilizar-se da perspectiva relacional em sua análise. 
uma perspectiva interseccional não significa, para ela, juntar duas coisas, porém analisar o contexto em que essas categorias emergem, demarcar como elas se encontram no discurso social e torná-las analíticas ao estudá-las em relação umas às outras.

Dentro das estruturas de relações sociais presentes na Apaga Fogueira, o gênero não é fator exclusivo de discriminação e/ ou diferenciação. Dessa forma, toma-se o gênero como um "elemento constitutivo das relações sociais baseado na diferença percebida entre os sexos" (Scott, 1995, p. 21). A diferença é vista aqui como uma possibilidade de entender a lógica imbricada nas relações sociais da Apaga Fogueira, visto que as relações sociais são estabelecidas e as diferenciações percebidas em seus momentos de sociabilidades durante os ensaios e as apresentações. Segundo Brah (2006), analisar a diferença a partir das relações sociais é perceber quais as circunstâncias sociais e culturais que fomentam as identidades dos grupos, como, por exemplo, o termo quadrilheiro.

Ser jovem participante da quadrilha que, por sua vez, é gerida por uma visão adultocêntrica ${ }^{11}$ heteronormativa ${ }^{12}$ e constituída por gerações distintas, também se torna um item de diferenciação. 0 desafio não se encontra somente em ser homem que se veste de mulher para dançar, mas também em se manifestar como homossexual em seu cotidiano. Ser jovem homossexual, que se considera pertencente a uma geração diferente das outras, e ser jovem numa instituição regulada por normas e regras regidas por adultos, que se entende por eles como fazendo parte de uma outra geração, com outros entendimentos sobre gênero e sexualidade, fazem parte das

11 Entende-se por adultocentrismo quando as regras estabelecidas são fomentadas, mediadas e regidas por um grupo de adultos.

12 Trata-se a heteronormatividade, na quadrilha junina, quando há a normativa performática do casal de quadrilheiro composto por um homem e uma mulher. 
tensões em tais relações. Dessa forma, "o conceito de articulação sugere relações de conexão e eficácia” (Brah, 2006, p. 352). Assim, é notório que a interseccionalidade estabelece, enquanto perspectiva de análise, uma relação entre as categorias: juventudes, geração e gênero.

A perspectiva interseccional que proponho é de não supervalorizar a categoria juventude, a de geração, a de gênero e nem a orientação sexual, mas me utilizar da articulação dos termos para entender o objetivo inicial desta pesquisa, quando se coloca o par masculino/feminino na representação da dança e quais as implicações disto nas sociabilidades e nos sentidos produzidos sobre os jovens quadrilheiros. É aí que a interseccionalidade opera analiticamente. Indica uma perspectiva relacional do que se pretende estudar sem necessariamente precisar operar de um lado ou do outro. Até porque a noção de gênero na Apaga Fogueira ocorre de forma relacional com as diferentes gerações presentes na instituição.

A proposta de trabalho com essas categorias é oferecer ferramentas analíticas para apreender a articulação de múltiplas diferenças e desigualdades. É importante destacar que já não se trata de diferença sexual, nem da relação entre gênero e raça ou gênero e sexualidade, mas da diferença, em sentido amplo para dar cabida às interações entre possíveis diferenças presentes em contextos específicos. (Piscitelli, 2008, p. 266).

Nota-se que um tema está entrelaçado ao outro se tornando impossível tratá-los isoladamente. Articular um conjunto de diferenças relacionadas às juventudes, à geração e ao gênero se torna propício a partir das narrativas dos integrantes da Apaga Fogueira e dos discursos das entidades que organizam as quadrilhas juninas em Sergipe. No contexto das competições juninas, as entidades que as organizam têm visões diferentes quanto ao fato de homens dançarem trajados com as vestimentas des- 
tinadas às mulheres. Assim, apresento a seguir as narrativas da FEQUAJUSE, da LIQUAJUSE ${ }^{13}$ e da Apaga Fogueira.

Para a FEQUAJUSE essa situação é possível, porém recente. Para eles, a possibilidade de inovação e incorporação de elementos novos à manifestação se tornava, às vezes, contraditória. Aceitavam a inovação relacionada às questões sobre o gênero, por exemplo e, em contrapartida, criticavam o uso de determinados tecidos, passos e instrumentos musicais que compunham o cenário das quadrilhas. 0 que fica claro nessa situação é que há um período de transição que dura alguns anos, considerado como um processo de reconfiguração (Santos, 2013).

A gente é da federação, nós criamos a federação sergipana das quadrilhas, a Liga é da outra TV [Atalaia], a gente é da TV Sergipe, a gente já tem dois anos que o homem pode entrar trajando de mulher, porque a gente já foi desclassificado viu, porque um componente nosso, eu achei uma ousadia da TV Sergipe, mandar que a gente levasse o componente, era homem, porque ele tava pintado, eles não aceitaram, isso tem dois anos viu, porque tinha um componente nosso que era totalmente caracterizado da maneira ele. (Mulher, 46 anos) ${ }^{14}$.

É notório perceber o papel heteronormativo da mídia nos concursos e como esta posição proíbe os transgêneros de participarem do processo de competições de quadrilhas juninas no Estado como tal. Segundo a entrevistada, havia uma inviabilização por parte dos organizadores do concurso no que se refere a participação dos transgêneros. Entretanto, esse cenário vem se reconfigurando e, nesse concurso especificamente, já há permissão que homens componham um casal de quadrilheiro, desde que um esteja vestido com os trajes femininos.

13 FEQUAJUSE - Federação das Quadrilhas Juninas do Estado de Sergipe e a LIQUAJUSE - Liga das Quadrilhas Juninas de Aracaju e Sergipe são os órgãos que representam as quadrilhas juninas no Estado.

14 Entrevista realizada no dia 06/04/2014 
Já para a LIQUAJUSE, o fato de homens se vestirem com roupas destinadas às mulheres é algo que interfere na pontuação da quadrilha. Se a quadrilha junina se apresentar nessa situação ela perde pontos, mas não é excluída da entidade, ou seja, ela continua filiada, mas sem poder participar de alguns concursos. De acordo com um membro da Liga, ao narrar as estratégias de inovação e abertura às inovações na quadrilha junina, ele aponta para debates sobre a discriminação, o gênero e a homossexualidade:

Nós temos que começar a tentar inovar um pouco. Não é discriminação, mas quadrilha aí fora usa muito homem vestido de mulher. A quadrilha junina ela é dita de um casal, um casal, um homem e uma mulher, que se você botar uma quadrilha com dois homens, mesmo trajando de mulher e um de homem, o poder físico daquele é totalmente diferente, a garra daquele, tudo, aquele homem que está trajado de mulher é totalmente diferente, então, aqui já está começando a entrar isso. Tem Estado como Pernambuco mesmo, que 80\%, 90\% das quadrilhas tudo tem homem vestido, e eu não sei se por motivo disso as mulheres tão saindo, porque nenhuma mulher que quer dançar ver uma quadrilha toda de homossexual, dançando, de mulher ela pode até não se sentir bem, pode acontecer isso. Então, não sei se é isso que tá acontecendo fora, se fosse um nível, número pequeno, 1, 2 ,3 quadrilhas, mas não, tem quadrilhas que tem $50 \%$, metade, então isso aí muda totalmente o foco (Homem, 49 anos) ${ }^{15}$.

A Liga justifica essa visão tomando como base a força física atribuída aos homens, o que compromete a evolução da apresentação da quadrilha. Assim, os vestidos são balançados com mais sagacidade segundo eles. Ou seja, a heteronormatividade aqui também está presente e se firma num discurso biológico, naturalizador da força como sendo propriedade dos homens. Para a 
Liga, à medida que a quadrilha autoriza a participação do sexo masculino vestido de mulher, ela está descumprindo o ordenamento da composição em pares formados por um casal, que, no entendimento deles, se dá entre um homem e uma mulher. Para eles, essa diferença é percebida na evolução da apresentação da quadrilha, pelos jurados e pelos próprios concorrentes, ou seja, os integrantes das outras quadrilhas.

É diferente de você pegar e botar 50 homens e 50 mulher e botar 75 homens e 25 mulheres, é totalmente diferente o trabalho. [Nas competições vocês verificam?] Os jurados percebem. E sem falar que as outras quadrilhas mesmo já vão dizer ói fulano de tal, aquele par ali ali e ali, eles mesmo vão dizendo. (Homem, 49 anos).

Já para a diretoria da Apaga Fogueira, que é filiada à FEQUAJUSE, essa situação já vem sendo aceita há alguns anos. Segundo eles, essa é uma forma de agregar mais jovens à quadrilha, tentar afastar os que são considerados vulneráveis e incluir os que não são aceitos em outras instituições.

Quer dançar de mulher, cada pessoa que chega, a gente respeita, arranje seu companheiro porque nossa sociedade é preconceituosa, totalmente, porque quando eles se vestem de mulher os homens não querem pegar na mão, então eles estão vindo com seus casais. Chegou quase ao ponto de desclassificar porque o homem estava vestido de mulher, quase, quase". (Mulher, 46 anos) ${ }^{16}$.

A partir da narrativa acima é notável que os homossexuais não são "aceitos" por todos da instituição aqui analisada. Para dançarem vestidos de mulher eles têm que adentrar à quadrilha com seu par predeterminado, visto que alguns se recusam a dançar

16 Entrevista concedida no dia 05/04/2014. 
com eles. Entretanto, não foi notado nenhum conflito físico ou verbal, ficando tais questões no plano simbólico e mais subjetivo dos processos de adesão ao grupo. Porém, no momento de execução da dança, quando há trocas de casais para formar determinada figura coreográfica, não havia hesitação dos membros heterossexuais nem nos ensaios e nem nas apresentações em contracenarem e dançarem, por curto espaço de tempo, com os homossexuais.

No cotidiano dos ensaios, eles se vestem com roupas que são associadas ao próprio sexo biológico, porém se utilizam de determinados objetos que são comumente relacionados ao sexo oposto como, por exemplo, bijuterias e maquiagens. No dia da apresentação eles se utilizam dos adereços e vestimentas para comporem o personagem cênico da mulher como mostra a figura abaixo. Dessa forma, poderia se considerar que eles se expressam como homossexuais cross-dressing trangêneros ao passo que vivenciam uma faceta do sexo oposto que está presente na performance da quadrilha junina.

Figura 3: casal de quadrilheiros formado por duas pessoas do sexo masculino.

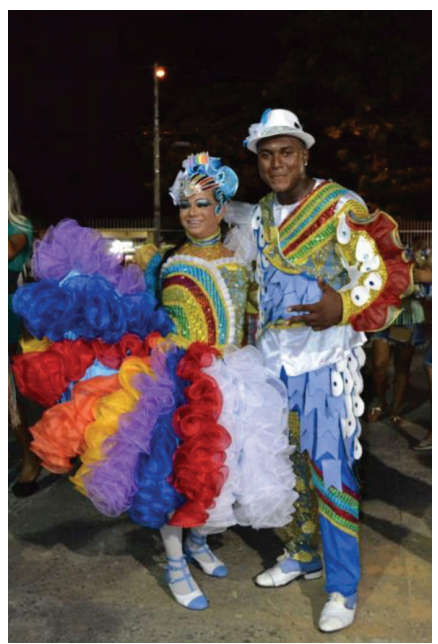

Fonte: Acervo Pessoal. 
A partir da foto acima, registrada no dia da competição, foi notória a maneira pela qual eles se exibiam aos flashes e às câmeras. As diferenciações entre os membros parecem desaparecer no momento de execução da dança e também nos bastidores no dia da competição. No dia 31 de maio de 2014, final da competição, os quadrilheiros chegaram ao Ginásio do Sesi ${ }^{17}$ em um ônibus locado por eles. Muitos não estavam totalmente arrumados.

Ao adentrarem no ginásio eram designados a um camarim na parte inferior às arquibancadas. Todos os integrantes utilizam-se desse espaço para finalizarem sua produção. Nesse ambiente não presenciei nenhum conflito quanto ao fato dos homens estarem se produzindo de mulher em meio aos outros integrantes. Segundo eles, a preocupação maior estava na apresentação do que em um possível desconforto com a situação.

Produzidos e apostos para adentrarem ao Ginásio, a quadrilha Apaga Fogueira contou com 20 pares de quadrilheiros totalizando $52 \%$ de homens e $48 \%$ de mulheres como mostrado anteriormente no gráfico. Além desses, estavam mais dois adultos, o casal formado por um homem e uma mulher, Abraão e sua esposa, e seis crianças representando os casais de animais, na encenação teatral, e, em média, uns 10 integrantes auxiliando nos bastidores. Com uma arca à frente, um tecido de aproximadamente 30 metros na cor azul simbolizava o oceano. Embaixo dele, encontrava-se a Apaga Fogueira. Assim, deu-se a entrada em cena da quadrilha na competição do Levanta Poeira. ${ }^{18}$

Nesse momento, os integrantes não mais manifestavam suas diferenças e diferenciações nos termos de Brah (2006), mas reverberam seus anseios coletivos e individuais, bem como a

17 SESI - Serviço Social da Indústria. O ginásio de SESI foi o local de realização do concurso de quadrilha junina Levanta Poeira.

18 A temática produzida, pela quadrilha junina em questão, para as competições no ano de 2014 foi: "Delírios de um dilúvio: o fim é o recomeço de um novo quadrilheiro". 
visibilidade alcançada, e deixavam transparecer seus sentidos ao estarem participando de uma manifestação para a qual se preparam o ano todo. Entretanto, as diferenças ainda estão lá, marcadas nos rostos maquiados e na produção feita para a apresentação.

Ser jovem, criança, adulto ou idoso; ser de uma geração globalizada, geração X ou @; ser mulher, homem, heterossexual, homossexual ou transexual; todas estas designações, tanto sociais quanto culturais, parecem não fazer sentido no momento da apresentação dos quadrilheiros, mas faz sentido em todas as suas trajetórias de vida e em seus cotidianos. No momento das apresentações, as diferenças e diferenciações parecem ser transcendidas pelo som que embala os corpos a dançarem e figurarem num espaço-tempo singular em que cada qual cumpre um papel social de gênero, enquadrando-se no masculino e feminino, mas ao mesmo tempo o transcende e o desassocia do sexo biológico.

Assim, não pretendo dizer que esses papéis sociais desapareçam do ensejo social no qual esses indivíduos estão envolvidos, mas se tornam camuflados pelas cores dos tecidos, pelas melodias escutadas e pelos cantos entoados pelos quadrilheiros quando estão em cena. Durante as apresentações estão suspensas, pelo menos entre os quadrilheiros que participam da dança, as subjetividades da geração e do gênero presentes no cotidiano e são reforçados os papéis masculinos e femininos típicos do formato da dança de pares e característicos das quadrilhas. A geração considerada mais jovem traz o que é visto como novidade para o comportamento social nas quadrilhas e aqueles que às dirigem repensam e dimensionam os dilemas das mudanças. 


\section{Considerações Finais}

No decorrer da pesquisa, desde os primeiros contatos até a elaboração deste texto, foi possível perceber o quanto a quadrilha é significativa para a comunidade local e para a história dos festejos juninos do Estado. Ficou notória a presença de gerações diferentes na quadrilha em questão, e que elas convivem num espaço propício à interação. Por ser gerida por uma visão adultocêntrica e heteronormativa e por uma geração considerada distinta, a quadrilha passa a tecer algumas adaptações para contemplar tanto os anseios de uma diretoria adulta quanto os desejos dos membros jovens. Assim, as diferenciações entre esses membros não se davam somente entre os considerados jovens e a geração adulta de mais idade, mas também em relação aos jovens autodeclarados homossexuais que dançavam vestidos com figurinos destinados às mulheres. Tornou-se claro que não há somente uma juventude quadrilheira, mas sim Juventudes atuando simultaneamente.

A partir da análise interseccional pude elencar como as juventudes se movem, são vistas e acionadas na quadrilha Apaga Fogueira. Ela possibilitou articular ideias que fomentassem o sentido de juventude sem ser necessário dissecar os termos referenciais: juventudes, geração e gênero. Trabalhá-los de forma relacional foi uma tática eficaz para poder perceber a importância das gerações e do gênero na composição da quadrilha em questão. Notei que indivíduos da chamada "melhor idade" e os adultos consideravam-se jovens por julgarem ter a vivacidade para dançar e a pontualidade no horário dos ensaios. Dessa forma, têm-se uma ideia de juventude acionada também de forma situacional.

Assim, ficou notório também que homens biológicos, do sexo masculino, dançam como mulheres em termos de performance de gênero, transcendendo categoriais sociais de forma situacional. Mas, por outro lado, ainda há a heteronormatividade no 
ideal de casal quadrilheiro, presente nas regras e falas de algumas instituições que afirmam que devem ser homens e mulheres biológicos e heterossexuais a compor este casal. E, mesmo quando se aceita uma diversidade de sexualidades, os papéis de gênero continuam a ser o de homem e de mulher nas quadrilhas juninas visto que não há o casal de homem com homem e mulher com mulher. É como se estabelecesse uma ruptura entre o que é biológico e o que é considerado social, entre sexo e gênero; há uma resistência a esta ruptura por partes das instituições regulamentadoras das quadrilhas juninas e, ao mesmo tempo, há uma perpetuação do ideário de casal heteronormativo e gênero composto, performaticamente, por um homem e uma mulher.

Todo o trabalho aqui apresentado foi feito tomando como base a pesquisa de campo junto a Apaga Fogueira. A imersão em campo foi surpreendente como exercício reflexivo. Trabalhar por meses junto a um grupo, conhecer trajetórias de vida diferenciadas e presenciar situações adversas em campo proporcionaram um conhecimento ímpar enquanto pesquisadora, mulher, em um ambiente diverso que impulsiona as sociabilidades, liberdades, as vezes comedidas, e interações. 0 campo abriu as possibilidades de acionar os sentidos e as reflexões sobre o universo das culturas juvenis, das quadrilhas juninas e das diferenciações.

Imagino que as questões aqui propostas poderiam ser percebidas em outras quadrilhas juninas, contudo, há a possibilidade de que algumas informações mais específicas conduzam outras pesquisas a resultados diferentes. E, assim, outros debates podem ser suscitados e mais densamente analisados como, por exemplo, as relações de gênero e os sentidos do masculino e do feminino no ambiente das quadrilhas juninas.

Abordar essa temática possibilita diversas entradas teóricas e metodológicas no campo da antropologia e demais ciências humanas. Mais especificamente para o interesse que desenvolvi aqui, os estudos sobre as quadrilhas juninas se configuram 
como um cenário novo e aberto a interconexões com outros trabalhos que tratem das culturas juvenis. Entretanto, foi um desafio estabelecer essa relação, pela escassez de trabalhos que contemplassem tal articulação. Dessa maneira, foi possível, ao que me pareceu, entender alguns dos sentidos múltiplos, diversos e híbridos constituídos sobre as interseccionalidades juvenis.

\section{Ref erências Bibliográficas}

ARAÚJO, Liana Matos. Juventudes e Quadrilha Junina: Estilos de Vida E Sociabilidades no Cenário do Consumo Cultural em Sergipe. São Cristóvão/SE, 2015. Dissertação (Mestrado em Antropologia) - Universidade Federal de Sergipe.

BRAH, Avtar. Diferença, Diversidade, Diferenciação. Cadernos pagu, 2006, p. 329-376.

BRASIL. Lei no 8.069, de 13 de julho de 1990. Estatuto da Criança e do Adolescente. Brasília, 1990.

BRASIL. Lei no 12.852, de 05 de agosto de 2013. Estatuto da Juventude. Brasília, 2013.

BUTLER, Judith. Undoing Gender. New York, Routledge, 2002.

CASCUDO, Luís da Câmara. Dicionário do Folclore Brasileiro. São Paulo: Edusp, 1988.

FEIXA, Carles. A Construção Histórica da Juventude. In: Jovens na América Latina. São Paulo: Escrituras, 2004. p. 257-327.

FEIXA, Carles e LECCARDI, Carmem. O Conceito de Geração nas Teorias Sobre Juventude. In: Revista Sociedade e Estado - Volume 25, №2 Maio/ Agosto, 2010.

FERREIRA, Felipe. Aqui, ali, em Todo Lugar. In: Inventando Carnavais. 0 surgimento do carnaval carioca no século XIX e outras questões carnavalescas. Rio de Janeiro: Ed. da UFRJ, 2005.

HALBWACHES, Maurice. A Memória Coletiva. São Paulo: Centauro, 2006.

MAGNANI, José. Os Circuitos dos Jovens Urbanos. In: Jovens na Metrópole: uma análise antropológica dos circuitos de lazer, encontro e sociabilidade. Tempo social, revista Sociológica da USP, 2005.p. 173-205.

PAIS, José Machado. Culturas Juvenis. Lisboa: casa da moeda, 2003. 
PISCITELLI, Adriana. Interseccionalidades, Categorias de Articulação e Experiências de Migrantes Brasileiras. Sociedade e Cultura, v.11, n.2, 2008, p. 263 -274 .

SANTOS, Eliseu Ramos. Festa, Tradição e Cultura Popular: Análise do processo de reconfiguração das quadrilhas juninas de Sergipe (1980-2000). 2013. Monografia de Ciências Sociais - Universidade Federal de Sergipe, São Cristóvão.

SCOTT, Joan Wallach. Gênero: Uma Categoria Útil para Análise Histórica. Educação \& realidade. Porto Alegre, vol. 20, no 2, 1995, p. 71 - 99.

Recebido em 20/01/2016

Aprovado em 20/05/2016 
